\title{
ORDEM E CAOS: UM CONCEITO ALTERNATIVO DE MERCADO
}

\section{ORDER AND CHAOS: AN ALTERNATIVE CONCEPT OF MARKET}

\author{
Édivo de Almeira Oliveira ${ }^{1}$ \\ William Barbosa ${ }^{1}$ \\ Clailton Ataídes de Freitas ${ }^{1}$
}

Recebido em: 19/02/2016 Aceito em: 22/06/2016

williambarbosa00@hotmail.com
Resumo: Mesmo constituindo-se um dos pilares de funcionamento do sistema capitalista, é bem verdade que o conceito de mercado não é consensual entre as distintas abordagens do pensamento econômico, dado as diferentes premissas e axiomas que fundamentam suas análises. Isto posto, o presente trabalho objetiva fornecer uma concepção holística e mais pragmática do mercado a partir dos conceitos de ordem espontânea, taxas naturais e expectativas racionais articulados com a Teoria do Caos. Com base nesses fundamentos teóricos conclui-se que o mercado é uma ordem espontânea evolutiva, repleta de relações não-lineares e formada por agentes autointeressados que, mediante processo de aprendizagem social, complexificam e aprimoram os padrões institucionais, culturais e técnicos que configuram o próprio mercado no transcorrer de um tempo dinâmico.

Palavras-chave: Teoria do Caos. Ordem Espontânea. Expectativas Racionais.

Abstract: Even being one of the pillars to the capitalist system operation, it is true that the concept of market is no consensus among the different approaches of economic thought, because of the different assumptions and axioms that underline its analysis. This paper aims to provide a holistic and pragmatic view of the market based on the concepts of spontaneous order, natural rates and articulated rational expectations with the Chaos Theory. Based on these theoretical foundations it can be concluded that the market is a spontaneous and in progress order, full of nonlinear relationships and made up by self-interested agents who, through social learning process, complicate and enhance the institutional, cultural and technical patterns what make up the market itself in the course of a dynamic time.

Keywords: Chaos Theory. Spontaneous Order. Rational Expectations.

\footnotetext{
${ }^{1}$ Universidade Federal de Santa Maria - UFSM - Santa Maria - Rio Grande do Sul - Brasil.
} 


\section{INTRODUÇÃO}

As premissas básicas e fundantes que regem o modus operandi dos mais diversos métodos e pressupostos epistemológicos, característicos de cada escola do pensamento econômico perpassam, necessariamente, pela definição do conceito explícito ou implícito do que seria o mercado e sua finalidade, bem como sua capacidade de gerar, via mecanismo de preços, alocações eficientes no sentido de Pareto ou uma alocação justa ${ }^{2}$.

No clássico conceito proposto por Adam Smith (1976), mercado é o locus em que ocorrem as trocas entre agentes autointeressados viabilizando a ação da mão invisível enquanto mecanismo último, cuja resultante direta seria o estabelecimento de uma ordem social que emana das interações pulverizadas e egoísticas estabelecidas entre os indivíduos. Hayek (1973), expoente da escola austríaca, aprofunda essa concepção de mercado ao sugerir o conceito de ordem espontânea de inspiração evolucionista, em que a aprendizagem social cumpre o papel basilar nas relações de troca, ao ser o fundamento que garante a harmonia e a complexificação dos sistemas sociais ao longo do tempo.

Mantendo-se fiel à tradição neoclássica, Friedman (1977) defende a noção de mercado como forma basilar de trocas e interações processadas entre indivíduos buscando seus próprios interesses, cujo equilíbrio exige como premissa incontornável a garantia do máximo respeito às liberdades individuais. Com vistas a fornecer uma explicação coerente com essa mesma noção de mercado, o autor elabora o conceito de taxas naturais demonstrando como as coerções e intervenções no processo produtivo e comercial entre os agentes sociais constituem uma perigosa interferência nas liberdades individuais e em distorções que afastam a economia do seu estado de equilíbrio.

A conclusão monetarista expressada acima acerca da natureza ontológica do mercado é radicalizada no arcabouço novo-clássico, dado que Lucas (1973) sugere de maneira convincente que os indivíduos tendem a não cometerem erros sistemáticos, uma vez que formulam suas expectativas de maneira racional, ainda que careçam de informação perfeita, tornando o mercado um sistema que tende inexoravelmente ao equilíbrio.

A supracitada explanação acerca das diferentes definições do que seria o mercado em uma economia capitalista, a partir dos expoentes de distintas escolas do pensamento econômico, revela que não se trata de um conceito simples e consensual. Com o propósito de aprofundar essa discussão e contribuir com o debate acadêmico, o presente trabalho pretende recuperar o conceito de ordem espontânea e articulá-la com a hipótese das expectativas racionais e de taxas naturais, no intuito de propor uma reflexão em que se acredita ser mais aprofundada acerca do funcionamento do mercado em uma economia capitalista.

Com vistas a obter-se um conceito de mercado que articule a noção de ordem social, com uma a noção funcional de equilíbrio não facilmente verificável no mundo real, emprega-se categorias analíticas consagradas em distintas escolas do pensamento econômico, uma vez que nenhuma escola em específico foi capaz de formular uma definição mais abrangente e pragmática do que seria o mercado. Portanto, enquanto a escola das expectativas racionais fornece subsídios analíticos

\footnotetext{
${ }^{2}$ Ver Varian (2006)
}

Estudos do CEPE [ISSN 1982-6729]. Santa Cruz do Sul, n. 43, p. 4-22, jan./jun. 2016. https://online.unisc.br/seer/index.php/cepe/index 
referentes ao comportamento microeconômico dos indivíduos no âmbito do mercado enquanto construto social, as noções importadas da abordagem monetarista e austríaca fornecem insights importantes para o entendimento da natureza macroanalítica e holística do mercado.

Para tanto, além dos fundamentos teóricos das distintas escolas de pensamento, brevemente apresentadas acima, faz-se necessário, também, importar da física e da matemática um instrumental analítico que permita compreender sistemas complexos, dinâmicos e não-lineares, denominado Teoria do Caos, de modo a fornecer insights a subsidiar o aprofundamento de um conceito de mercado como construto e ordem social.

Assim, diante da problemática exposta acima, expressa-se o problema que norteia o presente trabalho do seguinte modo: como a Teoria do Caos pode fornecer elementos teóricos-analíticos, que articulados com os conceitos de ordem espontânea, expectativas racionais e taxas naturais permitam formular um conceito mais abrangente, holístico e pragmático do mercado no sistema capitalista?

Para responder a esse problema de pesquisa delineia-se como objetivo geral: refletir como os elementos teóricos de distintas escolas de pensamento (austríaca, monetarista, novo-clássico) articulados com o construto teórico da Teoria do Caos possibilitam entender o mecanismo de mercado de modo mais abrangente e pragmático, ainda que ao custo de uma concepção holística.

O presente trabalho está estruturado em seis seções, contando com a introdução e as considerações finais. A Seção 2 traz as premissas básicas assumidas pela corrente austríaca e o conceito de ordem espontânea, que é de grande importância para o argumento basilar proposto neste estudo. Na Seção 3 está descrita a definição mais geral de taxas naturais proveniente dos monetaristas. A seção 4 descreve o argumento por trás do conceito das expectativas racionais dos novos-clássicos. Por fim, a Seção 5 aborda os aspectos conceituais da Teoria do Caos, enquanto na Seção 6 esse formalismo é articulado às definições desenvolvidas nas seções anteriores, na tentativa de sugerir uma nova e holística visão conceitual do mercado.

\section{A ESCOLA AUSTRÍACA E O CONCEITO DE ORDEM ESPONTÂNEA}

A Escola Austríaca surge no século XIX a partir dos trabalhos pioneiro de Carl Menger que definitivamente formula uma abordagem analítica que rejeita a teoria do valor-trabalho, até então, pensamento hegemônico entre os economistas, em favor de uma análise cujo pilar central seria constituído pela teoria da utilidade marginal do valor (VELOSO; ROSA, 2013).

A Escola Austríaca experimentou um certo apogeu por volta da década de 1930 do século passado, em função da atenção recebida pelos trabalhos de Friedrich Hayek na London School Of Economics. Todavia, essa popularidade sofre um "duro golpe" com a ascensão ideológico-político do keynesianismo, com a publicação da "Teoria Geral do Emprego do Juro e da Moeda" em 1936, que acabou por obscurecer academicamente as contribuições teóricas fornecidas por essa corrente até aquele momento.

Somente no final da década de 60 e início do decênio ulterior é que as até então favoráveis condições macroeconômicas, avultadas nos países capitalistas, durante a "época de ouro do capitalismo", experimentam um verdadeiro revés, cujos efeitos contrários à manutenção da 
predominância do keynesianismo, em termos mundiais, foram potencializados pelo receio em relação à expansão socialista. Esses acontecimentos geraram um ambiente que efetivamente concorreram em favor do ressurgimento da imagem pública e acadêmica de Friedrich Hayek, implicando em maior notoriedade para a Escola Austríaca (BARBIERI, 2008).

A Escola Austríaca está fundamentada em três conceitos básicos e precípuos para a sua construção enquanto formulação teórica dotada de fundamentos epistemológicos próprios, quais sejam: a ação humana, a concepção dinâmica do tempo e a limitação do conhecimento humano. $A$ ação humana no contexto da Escola Austríaca pode ser mais bem entendida e perscrutada a partir da praxeologia que nada mais é do que o campo científico responsável pela investigação da ação humana. Mises (2010) chega mesmo a afirmar que a premissa basilar que condiciona todas as ações humanas - inclusive nos âmbitos que extrapolam as práticas estritamente econômicas do homem, de modo a agregar as práticas humanas universais - seria a busca incessante dos indivíduos por maiores níveis de satisfação:

\footnotetext{
Os problemas econômicos ou catalácticos estão embutidos numa ciência mais geral da qual não podem mais ser separadas. O exame dos problemas econômicos tem necessariamente de começar por atos de escolha: a economia torna-se uma parte - embora até agora a parte elaborada — de uma ciência mais universal: a praxeologia (MISES, 2010, p. 23).
}

A segunda pressuposição básica da Escola Austríaca é aquela que concebe o tempo como uma categoria dinâmica e não mais uma categoria estática como aquela assumida pela teoria neoclássica de tradição marshalliana por força da inescapável influência da concepção newtoniana, e que se restringe a explicar o elemento temporal mediante o emprego de um simples eixo horizontal em que os intervalos temporais e o processo de aprendizagem ao longo do tempo são completamente ignorados. $\mathrm{Na}$ abordagem dinâmica do tempo, admite-se a inter-relação entre os infinitos pontos ou momentos no tempo e a capacidade de aprendizagem dos atores ao se deslocarem numa dimensão temporal. De forma mais precisa, a noção de praxeologia exige uma abordagem mais ampla do tempo, conforme explicado pelo próprio Mises (2010, p. 133):

\footnotetext{
A distinção epistemológica entre o sistema lógico e o sistema praxeológico consiste exatamente no fato de que este pressupõe as categorias tempo e causalidade (...). A diferença entre um e outro reside no fato de a praxeologia ter a mudança como um de seus elementos; as noções de mais cedo ou mais tarde e de causa e efeito fazem parte do sistema. Anterioridade e consequência são conceitos essenciais no raciocínio praxeológico; o mesmo ocorre com a irreversibilidade dos eventos.
}

A terceira premissa basilar é a própria limitação do conhecimento humano, que constitui o seu argumento epistemológico fundante e de grande importância para a estruturação lógico-racional que sustenta a concepção austríaca não só do homem e da economia, mas também do próprio mercado. Hayek (1973) advoga em favor da inerente incapacidade humana de ter acesso e processar toda a gama de informações existente, implicando em admitir que o conhecimento seja intrinsecamente limitado.

Ora, se o conhecimento humano é limitado, obviamente, deve-se também admitir que as ações e o comportamento humano, em linhas gerais, sejam caracterizados por propriedades como o 
de imprevisibilidade e indeterminação. Em certa medida, a imprevisibilidade e a indeterminação são os elementos que irrevogavelmente impõem limites à mente humana, no que se refere a sua capacidade de compreender, pelo menos integralmente, todos os fenômenos econômicos e sociais (IORIO, 2011).

Com efeito, as três supracitadas concepções principais da Escola Austríaca se manifestam de forma mais realística no caráter altamente subjetivista e individualista na abordagem da supracitada corrente, bem como na sua estruturação analítica com ênfase no famoso conceito de utilidade marginal cuja formulação no escopo do pensamento econômico se deve a três economistas, conhecidos como marginalistas, imbuídos de originalidade, a saber: Carl Menger (1871), Leon Walras (1874) e Stanley Jevons (1871).

Nesse contexto, é importante esclarecer que para os austríacos o processo investigativo deve reconhecer que a motivação subjetiva por trás de toda a ação humana isolada e individual é a elevação de sua utilidade ou satisfação e que, em última instância, permite a formação daquilo que se convencionou chamar de "sociedade". Feijó (2000, p. 106) sintetiza bem a intrínseca e intricada relação estabelecida pelos conceitos de subjetivismo, maximização da autossatisfação e de ação humana no pensamento austríaco:

\footnotetext{
O axioma da racionalidade de toda ação voltada ao alcance de maior satisfação individual é o ponto de partida da análise praxeológica. A ação em Mises é um conceito inseparável da ideia de racionalidade. Mises rejeita todo critério exógeno de definição de racionalidade. Os elementos subjetivos que comandam a ação do homem não podem ser previamente identificados, são as escolhas do agente que demonstram as suas avaliações subjetivas.
}

Hayek (1973) avança em sua análise acerca da importância da limitação do conhecimento humano, dado que para o mesmo a informação não só é incompleta no escopo do sistema econômico, como se encontra pulverizado no locus da mente de cada indivíduo. Para Hayek, a maior parte dessas informações não estaria armazenada na mente humana sob a forma de teoria formal, mas sim, sob a forma de conhecimento tácito adquirido com base nas suas experiências práticas e nas situações conjunturais cotidianas.

Deste modo, pode-se afirmar que essa complexa rede formada pelas informações incompletas, pulverizadas, não formalizadas e, não raras vezes, conflitantes e contraditórias entre si é que levou os austríacos a rejeitarem qualquer teoria econômica baseada no equilíbrio de mercado e a repudiarem as sugestões históricas e intervencionistas de coordenação do mercado. Ora, se um sistema é composto por pessoas dotadas da capacidade de aprendizagem e de transmitirem conhecimento, logo, o próprio sistema tende a experimentar aperfeiçoamentos ao longo de um tempo dinâmico.

Assim, Hayek (1973) concebe o conceito de ordem espontânea para a explicação da sociedade e do próprio mercado, enquanto construções sociais, os quais são resultantes de uma série de variáveis e fatores integrados em um ambiente que aparentemente configura um estado intricado e complexo, conforme o autor: 
deal with a directed social order, as an organization. The grown order, on the other hand, which we have referred to as a self-generating or endogenous order, is in English most conveniently described as a spontaneous order (HAYEK, 1973, p. 37).

Portanto, os indivíduos seriam autointeressados e dotados de limitada capacidade de processarem e armazenarem conhecimentos, o que implica em afirmar que os mesmos estarão constantemente revisando suas previsões e, consequentemente, criando novas expectativas. Em função disso, o mercado manifesta uma tendência a uma completa coordenação, no entanto, sem nunca alcançá-lo, dado a reconfiguração das próprias relações de trocas causadas por revisões e pelas mutações das expectativas que essas frequentes revisões implicam, sobretudo, aquelas ocorridas no âmbito do sistema de preços. Nesse sentido, a função precípua do mecanismo de preço seria emitir os sinais necessários para que o mercado consiga efetuar esses incessantes ajustamentos, causados por mudanças de previsões e eventualidades que podem ser inicialmente não tão significativas, mas que com o transcorrer do tempo adquirem repercussões substanciais, gerando um estado de não-equilíbrio.

Para a construção do conceito de mercado perseguido pelo presente estudo, a noção de mercado enquanto ordem espontânea é central. Portanto, longe de constituir uma formulação completamente original, busca-se estritamente identificar um instrumental analítico que seja coerente com a visão de mercado enquanto ordem espontânea, e que avance em relação àquela visão linear, determinística e estática, ainda que ao preço de uma visão fundamentalmente holística desse construto conceitual. O próximo passo nesse intento é resgatar o conceito de taxas naturais formulada pelos monetaristas, para que mais adiante se discuta como o conceito de equilíbrio, tão cara e funcional para o pensamento econômico, harmonizado com a ideia de não-equilíbrio defendida por Hayek (1973), até então pouco compatível com a noção de ordem espontânea.

\section{MONETARISMO E AS TAXAS NATURAIS}

Milton Friedman é, reconhecidamente, o instituidor e principal expoente do monetarismo em sua versão moderna, teoria essa que tem suas origens ainda no século XVIII, com os notáveis trabalhos de David Hume em 1752, posteriormente refinados por James Angel (Universidade de Colúmbia) e, sobretudo, pelos economistas de Cambridge (CORAZZA; KREMER, 2003). A ideia central defendida por esses teóricos consiste na defesa de que os desequilíbrios monetários seriam a principal causa dos desequilíbrios econômicos reais. Não faz parte do escopo deste trabalho o aprofundamento das questões macroeconômicas e de políticas monetárias ou fiscais dessa corrente, mas sim o revolucionário e influente conceito de taxas naturais de desemprego e do produto intrínseco a cada sociedade defendida por Friedman e seus corolários. A hipótese de uma taxa natural de (des) emprego e do produto é o sustentáculo no qual Milton Friedman constrói o arcabouço teórico que a partir da década de 1970 passou a exercer forte influência sobre a política e a economia. Vale dizer que Friedman emprega o conceito de "natural", segundo Sicsú (1997), em um 
sentido fundamentalmente wickselliano ${ }^{3}$ ao discutir os efeitos da política monetária e fiscal sobre o produto e o emprego. Em síntese, o que essa hipótese sugere é que há um nível de produto e emprego intrinsecamente correlacionado aos fatores reais da economia em uma dada comunidade.

Deste modo, Friedman (1968) reconhece que as sociedades apresentam um determinado estado dos fatores reais da economia (tecnologia, população, preferências intertemporais, entre outros) que leva o produto e o nível de emprego a apresentarem certa tendência a oscilarem em relação a um nível compatível com o estado real desses fatores nessas mesmas sociedades, justificando a opção pelo emprego de termo "natural" pelo autor e seus corolários. Friedman (1968) entende essas taxas naturais como àquela compatível com o nível de uma variável no equilíbrio, considerando-se tanto as características estruturais, quanto as institucionais do mercado de fatores e de bens, não os confundindo com os afastamentos dessas variáveis de suas taxas naturais por conta das discricionárias intervenções monetárias.

O conceito de taxa natural é o construto teórico que permite aos monetaristas demonstrarem a ineficiência da adoção de políticas de caráter intervencionista, dado que os fatores reais determinantes da oferta estariam, nesta perspectiva, intrinsecamente associados a um dado nível "natural" de produto e emprego; cujas tentativas sistemáticas em superá-las, sem a realização de mudanças nas variáveis reais da economia, poderiam até mesmo lograr êxito no curto prazo, porém, no longo prazo o produto e emprego tenderiam a retornar para seus níveis naturais, acompanhado de maiores níveis de preços.

O conceito de taxas naturais intrinsecamente associadas a um nível dado de conhecimento, tecnologia, fatores de produção, entre outros, é um argumento racionalmente forte e se, por vezes, é questionado, isso se deve pelo fato de situações de equilíbrio ser de difícil identificação nas realidades factuais, em que pese sua inquestionável funcionalidade analítica para o pensamento econômico. Todavia, talvez seja possível explicar tanto essa dificuldade de se constatar empiricamente um equilíbrio perfeito nos mercados, quanto compatibilizá-lo com a abordagem hayekiana de ordem espontânea evolutiva, a partir do fundamento explicativo fornecido pela escola novo-clássica, ao argumentar que os indivíduos tendem a não cometerem erros sistemáticos, ainda que passivos de errarem e ajustarem suas expectativas em prazos mais curtos. Para tanto, na próxima seção se realiza uma breve recuperação das premissas avultadas pelos novos-clássicos, para que na sexta seção tais ideias sejam articuladas com o intento de se alcançar o objetivo proposto no presente estudo.

\section{NOVO-CLÁSSICOS E A HIPÓTESE DAS EXPECTATIVAS RACIONAIS}

Embora o conceito de expectativas racionais tenha sido formulado por John Muth (1961), apenas com o trabalho elaborado por Robert Lucas (1973) é que se estabelece o marco inicial da corrente do pensamento econômico denominado de nova economia clássica, mediante um trabalho que objetivou analisar a eficácia das políticas intervencionistas do Governo na economia.

A ideia defendida por Lucas (1973), bem como por Sargent e Wallace (1975), é que uma vez

\footnotetext{
${ }^{3}$ Wicksell foi o pioneiro ao usar o conceito "natural" na formulação de uma teoria da taxa de juros de longo prazo.
} 
antecipada pelos agentes, às políticas econômicas seriam ineficazes em função das características inerentes aos indivíduos que são suficientemente racionais para que, utilizando-se das informações disponíveis e mais relevantes no processo de formação de suas expectativas, não cometam erros sistemáticos. Assim, uma vez que uma política econômica se apresente previsível a tal ponto que possa ser antecipada pelos indivíduos, esperar-se-ia que a intervenção governamental perdesse sua eficácia.

Para Lucas (1972), os agentes formam suas expectativas a partir das esperanças condicionais das variáveis observadas, com base nas informações relevantes disponíveis. Assim, previsões antecipadas introduzidas na formação das expectativas desses agentes evitam erros sistemáticos ao longo do tempo, muito embora a ocorrência de erros seja humanamente inevitável, sobretudo, no curto prazo.

Assim, o conceito de ordem espontânea esclarece que sistemas (como o mercado) evoluem em função do aprimoramento e do acúmulo de conhecimento viabilizado pelo processo de aprendizagem das instituições e dos indivíduos. Uma das ideias que o presente trabalho pretende exprimir é que esse argumento não é incompatível com a noção de que o mercado, em uma determinada economia num dado momento no tempo, apresente certa configuração das suas variáveis exógenas e endógenas (expectativas subjetivas, fatores de produção, nível tecnológico, etc.) intrinsecamente associada ao nível de produção, emprego e ao nível máximo de intercâmbio comercial subjacente a estrutura produtiva, institucional e ao estado do conhecimento apresentado por essa mesma economia. Ou seja, mesmo sendo uma ordem espontânea de não-equilíbrio, o mercado se desloca em relação a níveis que se poderia chamar de taxas naturais.

Para que esse ponto de vista fique mais claro e se alcance o conceito aqui perseguido é de basilar importância importar um instrumental analítico próprio da física e da matemática com o intuito de se buscar elementos que cumpram o papel de elo que engendre coesão entre os conceitos de ordem espontânea, expectativas racionais e taxas naturais; cujo instrumental estático-comparativo consagrado pela abordagem atual da macroeconomia e microeconomia se apresenta claramente incapaz de fornecer. Deste modo, a seção abaixo objetiva trazer esclarecimentos acerca do conceito e da formalização da Teoria do Caos para que na seção subsequente seja articulada com os conceitos econômicos abordados até aqui, com o intuito de se avançar na compreensão, ainda que exploratória e holística, de um conceito mais pragmático e realístico do mercado.

\section{FUNDAMENTAÇÃO TEÓRICA DA TEORIA DO CAOS}

Em 1962, Edward Lorenz concluiu, com base em recursos matemáticos, que a meteorologia é um sistema bastante complexo, no sentido de que mudanças no seu estado inicial, por menores que sejam, podem ser o fator causal de mudanças em cadeia numa magnitude tal que implique não só em distorções quantitativas, mas também em alterações qualitativas substanciais em relação aos desdobramentos esperados antes da ocorrência das mudanças no estado inicial do sistema avaliado. Em função disso, Lorenz cunhou uma metáfora bastante conhecida que foi o título de um dos seus trabalhos mais conhecidos e que, em que pese seu caráter bastante curioso e pitoresco, ilustra muito 
bem o âmago daquilo que seria conhecido como Teoria do Caos e que pode ser reproduzida nos seguintes termos: "Predictability: Does the flap of a Buterfly's wings in Brazil Set Off a Tornado in Texas?" (LORENZ, 1979).

Conforme Prigogine (1996), o objeto de estudo da Teoria do Caos são sistemas de feedback não-lineares (ex: células, fenômenos meteorológicos, empresas, dentre outros) e que se caracterizam pela impossibilidade de se obterem previsões precisas em espaços temporais maiores, dado que são sistemas inerentemente sensíveis às condições iniciais internas e externas aos mesmos. Portanto, em um sistema caótico bastam apenas mudanças ínfimas nas condições inicias para que os resultados em períodos mais longos se tornem imprevisíveis.

É bom que se diga que o termo "caos" é um tanto impreciso, uma vez que para o próprio Lorenz (1996) o caos seria uma espécie de ordem mascarada de aleatoriedade. Portanto, o caos nos termos preconizados por essa teoria se refere menos a um estado absoluto de desorganização, do que a leis e fenômenos ordenados que em períodos mais elásticos engendrem imprevisibilidade e imprecisão nas tentativas de serem previstas.

O fato é que um sistema não-linear, caótico e aperiódico é, em linhas gerais, sensível às mudanças em seu estado inicial, e a transição de um estado para outro não pode ser descrita com exatidão em períodos mais longos, logo, restando apenas o recurso de descrevê-la em termos probabilísticos. Assim, o transcorrer de um mesmo período de tempo em momentos distintos, apenas acidentalmente convergirá para um comportamento perfeitamente idêntico do sistema em ambos os casos. Em que pese a possibilidade de serem realizadas certas previsões mais acuradas em períodos bem próximos da ocorrência de um ruído (perturbações e erros) que altere o estado inicial do sistema, em espaços temporais mais elásticos, as repercussões em cascata dos mecanismos de feedback (retroalimentação) acabam por potencializarem os efeitos dessas alterações ao longo do tempo.

Em suma, quanto maior for o tempo transcorrido entre o momento que se pretende inferir previsões e aquele em que ocorreu certa perturbação que modificou o estado inicial do sistema, maiores serão as a dificuldades de se obterem previsões exatas. Leffa $(2006$, p.33) explicita muito bem as peculiaridades desse tipo de sistema do modo como segue:

\footnotetext{
Ao estudar um sistema, não é permitido fragmentá-lo em segmentos sem levar em consideração o contexto em que eles estão situados e suas relações com todos os outros segmentos. A soma de cada segmento não reflete a realidade do sistema porque ele é dinâmico e evolui com o tempo à medida que os segmentos vão interagindo uns com os outros e, dessa maneira, introduzindo modificações no próprio sistema.
}

Com efeito, as duas maiores propriedades de um sistema não-linear caótico consistem: (a) na sua sensibilidade às condições iniciais; (b) e na sua capacidade de reagir a qualquer perturbação externa. Enquanto a primeira está relacionada com os mecanismos de feedback, isto é, de reações em cadeia que potencializam o distanciamento do sistema daquele esperado antes da ocorrência do ruído; na segunda propriedade fica evidente que um sistema caótico e complexo, a exemplo do corpo humano, longe de ser fechado em si mesmo, caracteriza-se por sua sensibilidade a estímulos e interferências externas (LEFFA, 2006).

Estudos do CEPE [ISSN 1982-6729]. Santa Cruz do Sul, n. 43, p.4-22, jan./jun. 2016. 
Segundo Leffa (2006), um sistema caótico está fundamentado em um comportamento de auto-organização, no sentido de que as partes interagem e se comunicam espontaneamente entre si, de maneira que, em última instância, implique na ocorrência de um processo de autocoordenação ${ }^{4}$, logo, sem a necessidade de um comando central. Conforme Barbosa e Crispim (2006), esses sistemas também apresentam a característica de serem adaptativas ao modificarem suas ações e funções na medida em que ocorrem os processos de interação e transição, dado que a perfeita estabilidade comprometeria a capacidade do sistema em sobreviver às diferentes situações e mudanças externas.

Por sua vez, Paiva (2001) ressalta que uma característica dos sistemas caóticos é a autossimilaridade, que consiste na existência de certos padrões dentro dos próprios padrões gerais de um sistema - ainda que não idênticos - numa visão cada vez mais microscópica do sistema em análise. Em outras palavras, seria a repetição do padrão observado no sistema como um todo em cada uma das suas partes, numa escala cada vez menor (similar a uma visão em zoom), processo esse denominado pelos autores da Teoria do Caos de escalonamento. $\mathrm{O}$ autor sugere como exemplo uma árvore em que seus galhos apresentem bifurcações em escala cada vez menores, até chegar nas micro-nervuras de suas folhas. Uma observação minuciosa dessa mesma árvore permitirá observar que há um certo padrão em suas bifurcações, de maneira tal que é como se pudesse ser enxergado o todo em qualquer uma das partes dessa árvore, e vice-versa. É justamente essa curiosa estrutura formada por autossimilaridades e escalonamentos que se denomina de fractal.

Barbosa e Crispim (2006) explanam que os sistemas complexos e não-lineares, em que pese à impossibilidade de previsibilidade absoluta que os circundam, apresentam atratores estranhos, isto é, uma tendência auto-organizativa em torno de um comportamento fractal que configura, grosso modo, as posições preferidas do sistema em torno de um padrão definido por conta de uma força de ordenação por trás desses fenômenos. Portanto, ainda que exista certa aleatoriedade, o comportamento do sistema fica restrito a um determinado padrão não exatamente idêntico por não ser determinístico, mas que não se afasta demasiadamente de certo padrão definido de comportamento - como as ondas que uma gota d'água produz ao tocar um copo com água.

Cumpre dizer que esses sistemas apresentam quebras de simetria, ou seja, constantes desarranjos de uma configuração mais geral ordenada, e que pode vir a resultar em outras configurações tanto ordenadas, quanto desordenadas. Nesse sentido, as mudanças ocorridas comportam um período de transição que requer entradas contínuas de estímulos (energia). Como conclui Paiva (2001), esse estado de coisas só pode implicar, obviamente, em um sistema invariavelmente instável e complexo.

Cumpre esclarecer como se identificar e distinguir sistemas caóticos de outros tipos de sistemas. Um dos métodos apresentados por Paiva (2001) é o expoente de Lyapunov. Como já discutido acima, umas das características basilares de um sistema caótico é que pontos inicialmente próximos com o tempo passam a se localizarem cada vez mais distantes. Deste modo, dois pontos que no momento inicial estão separados apenas por $€$, com a ocorrência de $N$ passos se tornam

\footnotetext{
${ }^{4}$ Embora Hayashi (2002) explicite que existem diferenças entre a teoria do caos e da complexidade, de modo que o conceito de auto-organização esteja mais associado a essa última, o presente trabalho se insere nessa discussão aceitando a teoria do caos como uma disciplina mais abrangente da qual a própria abordagem da complexidade faz parte.
} 
separados por exp $(\mathrm{N} \lambda)$, onde $\lambda$ é denominado de expoente de Lyapunov. Assim, quando $\lambda$ é negativo o sistema é estável, quando $\lambda$ for nulo o sistema apresenta oscilações periódicas, e quando $\lambda$ for positivo o sistema é caótico.

Os sistemas caóticos, embora apresentem certa aleatoriedade, sobretudo, no longo prazo, não se confundem com sistemas que são exclusivamente randômicos. Nesse sentido, Stacey (1995) explana que o método pautado na análise dos erros de predição pode fornecer subsídios analíticos interessantes para a distinção dos mesmos. Ora, enquanto um sistema caótico suporta previsões de curto prazo - sendo somente o longo prazo difícil de ser previsto com exatidão - um sistema meramente randômico e, consequentemente, puramente aleatório, não comporta possibilidades de previsões tanto no curto, quanto no longo prazo. Portanto, a análise dos erros das séries de períodos mais elásticos permite identificar se um dado sistema é caótico ou não. Claro que esses são só dois de vários métodos levantados pela literatura para identificação de sistemas caóticos.

Para o objetivo do presente trabalho, os instrumentos analíticos fornecidos pela Teoria do Caos são fundamentais. Isso porque um maior aprofundamento do conceito de mercado deve romper com uma análise estática-comparativa, apresentando uma análise dinâmica e evolutiva dos processos que o envolve ao longo do tempo. Além disso, acredita-se que um conceito mais abrangente de mercado deve permitir conciliar a noção de mercado enquanto ordem social, formada por uma infinidade de indivíduos com uma a noção funcional de equilíbrio não facilmente verificável no mundo real. Ou seja, a noção de mercado deve responder ao duplo questionamento: a) como esse sistema (mercado) experimenta evoluções? b) como explicar o fato desse suposto equilíbrio ser tão dificilmente verificável?

Muito provavelmente se pode avançar nessa perspectiva empregando a Teoria do Caos como fundamento analítico que configure um elo entre os fundamentos teóricos relacionados à ordem espontânea, às taxas naturais e às expectativas racionais, que mesmo advindos de correntes distintas, configuram elementos conceituais que estão por trás e norteiam as relações de trocas e produtivas nas economias capitalistas. Entende-se que esses conceitos, quando articulados entre si, para além das acepções ideológicas, com vistas a perscrutar a realidade factual, poderão fornecer uma visão holística e ao mesmo tempo mais precisa sobre a ontologia que envolve o mercado. Uma sugestão de como isso poderá ocorrer segue na interpretação construída na seção a seguir.

\subsection{Hipóteses Básicas Assumidas e a Teoria do Caos como Proposta Metodológica e Conceitual do Mercado}

Não se faz necessário um grande esforço intelectual para se perceber um paralelo, ou pelo menos a ausência de contradições teóricas graves, na hipótese das expectativas racionais dos novos-clássicos com a premissa austríaca que preconiza a busca pela satisfação a nível do indivíduo como motivação precípua dos agentes, bem como o conceito de mercado (e mesmo de sociedade e de linguagem humana) como ordem surgida e desenvolvida espontaneamente mediante tentativas $e$ erros do homem que aprende e, consequentemente, aperfeiçoa o próprio sistema de qual faz parte.

Isso porque se para os adeptos da hipótese das expectativas racionais, os erros sistemáticos

Estudos do CEPE [ISSN 1982-6729]. Santa Cruz do Sul, n. 43, p.4-22, jan./jun. 2016. https://online.unisc.br/seer/index.php/cepe/index 
são evitados pelas pessoas, deve-se admitir que em um período de tempo menos elástico e insuficiente para que ocorra o aprendizado dos indivíduos, é inescapável a admissão da ocorrência de erros para que, só então, esses mesmos indivíduos sejam capazes de abalizarem e processarem esses mesmos erros com vistas a impedirem que eles ocorram de maneira reincidente e os prejudiquem na consecução dos seus objetivos pessoais. Deste modo, considerando-se que não só os indivíduos como as próprias instituições evoluem - mediante rotinas, cultura, entre outros, abalizadas mediante tentativas e erros que permitem o acúmulo de conhecimento científico e tácito (não-formal) oportunizadas pela aprendizagem social—, como preconizada por Hayek (1973), o que se tem é a formação de sistemas como o mercado que se aprimoram gradativamente ao longo da história tornando-se mais complexa e imprevisível.

Hayek (1979), inclusive, chega a apontar o respeito pelas cláusulas contratuais, a noção formal de terras e de propriedade privada em geral como provas cabais da capacidade de uma ordem social e espontânea evoluir ao longo do tempo em função do processo de aprendizagem social. Uma análise mais pragmática da realidade econômica concreta exige que seja aceita a pressuposição elementar de que os indivíduos, ainda que aprendam com seus erros e acertos, formam um sistema complexo e caótico, chamado de mercado, em que o processo de tentativas e erros individuais constitui o mecanismo último de aperfeiçoamento auto-organizativo básico do próprio sistema.

Deste modo, infere-se que o mercado quando não resumido a poucos agentes, pode muito bem ser concebido como uma ordem espontânea evolutiva e, adicionalmente, como um sistema caótico auto-organizativo. Aliás, a noção de mercado enquanto sistema complexo e evolutivo já tinha sido proposto por Parker e Stacey (1995) e Barbosa e Crispim (2006). O fato é que para além do proposto por esses autores, o que se defende no presente trabalho é que o mercado pode ser compreendido como um sistema complexo que evolui ao longo do tempo; além de ser imprevisível em termos precisos no longo prazo, porém, dotado de certo grau de organicidade, desde que mantido os pressupostos básicos da Escola Austríaca de homem autointeressado, racional e de conhecimento limitado - ou mesmo a hipótese das expectativas racionais quando considerado um período de tempo insuficiente para serem evitados os erros individuais.

Compreende-se que o homem submetido a uma inerente racionalidade limitada em um ambiente de informação incompleta nem sempre tomará a melhor decisão e conseguirá evitar os erros de curto prazo, e nem mesmo utilizará e processará todas as informações relevantes disponíveis, dado que a limitação de seus conhecimentos o impulsiona muitas vezes a agir por força dos meros "instintos" menos racionais da natureza humana. Todavia, em consonância com o que fora defendido por Hayek (1973), após uma série de rodadas de ações desses mesmos agentes por intermédio do processo de tentativa e erro os agentes adquirem e acumulam conhecimentos, sendo em função disso que, conforme previsto por Lucas (1972), os erros sistemáticos poderiam vir a serem, grosso modo, evitados em períodos de tempo mais elásticos.

Em suma, as limitações humanas em termos de conhecimento é a causa primeira das gerações de "ruídos", ou seja, dos erros e perturbações que impedem o alcance dos resultados mais eficientes e afastam o mercado do estado de equilíbrio perfeito, dado que as revisões das previsões e as mudanças nas expectativas resultarão em mutações na configuração do próprio mercado, 
tornando o que seria o ponto de equilíbrio no momento anterior, não mais o estado de equilíbrio depois de sucedidas tais mudanças nesse mesmo mercado, configurando um sistema caótico de não-equilíbrio, como preconizado por Hayek (1973).

Ou seja, o mercado apresenta certa atração para determinados estados de equilíbrio, sem que não necessariamente o alcance em função das frequentes alterações e ruídos nas condições iniciais, dado a alta sensibilidade do mercado a esse tipo de mudanças, ainda que ínfimas. Esses estados estão associados às taxas naturais de emprego e produto defendidas por Friedman (1968) que resultariam em um nível máximo de procura e demanda em pleno emprego, gerando certo padrão similar a um atrator estranho numa topologia aproximadamente fractal ao longo de períodos mais longos. Empregando um argumento semelhante em essência àquele utilizado por Stacey (1995) para explicar a dinâmica das organizações, poder-se-ia defender que no mercado os atratores estranhos seriam cada nível de tecnologia, conhecimento, fatores de produção e fatores subjetivos (costumes, tradições, expectativas, etc.) dados em determinado momento numa sociedade que representariam certa força de atração para certos níveis e taxas naturais mais prováveis e intrinsecamente associados a esses fatores em conjunto. Como os fatores objetivos e subjetivos elencados se alteram ao longo do tempo, espera-se que justamente em função disso os níveis e as taxas naturais também se alterem ao longo do tempo.

A capacidade de aprendizagem dos indivíduos estaria por trás da capacidade desse sistema, no longo prazo, de adquirir alguma organicidade que permite aos economistas e especialistas muitas vezes preverem, em linhas gerais, o seu comportamento, não obstante, previsões precisas sejam excessivamente difíceis de serem realizadas. Isso pelo fato do mercado ser altamente sensível às condições iniciais por força do inescapável processo de constantes revisões de expectativas ou eventos circunstanciais e aleatórios externos; de modo que tenda a se movimentar em torno de suas taxas naturais, porém apenas acidentalmente ou por curtos períodos alcance o equilíbrio pleno por força das constantes revisões de expectativas realizadas pelos agentes individuais. Em suma, tem-se uma ordem espontânea evolutiva de não-equilíbrio, mas que ao longo do tempo se desloca em torno de certos níveis naturais que se modificam ao longo do tempo.

Na noção defendida no presente estudo, o mercado surge de uma intricada e "emaranhada" rede de pessoas inerentemente autointeressadas por intermédio das relações comerciais e produtivas, caracterizada pela imprevisibilidade e indeterminação oriundas do conhecimento limitado que condicionam as relações humanas elucidadas por Hayek (1973). Ainda que os papers e manuais de economia estejam repletos de tentativas de exprimir relações lineares entre variáveis, o fato é que a devida explicação do comportamento do padeiro, açougueiro e cervejeiro ${ }^{5}$ - para invocarmos uma célebre ilustração de Smith (1976) —, exige a priori o reconhecimento do caráter imprevisível, indeterminado e limitado da natureza e do conhecimento humano.

Claro que tal especulação teórica formulada até aqui não se sustenta em um mercado composto por uns poucos agentes, uma vez que em tal situação o argumento da pulverização das ações e o caráter de não-centralidade perdem suas consistências, tornando mais tênue à

\footnotetext{
${ }^{5}$ Célebre ilustração da "mão-invisível" formulada por Adam Smith na sua obra que é amplamente considerada como o marco inicial da Economia Moderna intitulada "Uma Investigação Sobre a Natureza e as Causas da Riqueza das Nações" publicada originalmente em 1776.
} 
identificação do mercado como uma ordem espontânea hayekiana. Contudo, uma vez satisfeita a premissa do mercado ser composto por uma ampla quantidade de agentes, defende-se aqui que alterações nas previsões individuais, tão ínfimas em relação ao mercado como um todo - mas que geram efeitos consideráveis quando em cadeia e com o transcorrer do tempo dinâmico -, geram novas configurações do próprio mercado, colapsando qualquer argumento em favor de uma propriedade intrinsecamente determinística, pelo menos numa escala de tempo maior. Todavia, é possível admitir que esse emaranhado e confuso sistema obedece alguma regularidade quando considerada uma escala de tempo mais elástica, o que justifica o fato de que as variáveis componentes do mercado tendem para certos estados e níveis chamados pelos monetaristas de taxas naturais, cuja atração seria exercida pelos atratores estranhos. Não obstante, nada leve a constatar que seja possível previsões exatas de tão complexo e caótico sistema no longo prazo, gerando um estado de não-equilíbrio defendido por Hayek (1973).

Em síntese, o que se procurou demonstrar é que a aceitação de algumas premissas formuladas por distintas correntes do pensamento econômico (conhecimento limitado, tempo dinâmico e capacidade de aprendizagem, taxa natural, entre outros) e a existência de uma ampla gama de agentes pulverizados permite conceber o mercado como um sistema complexo repleto de relações não-lineares entre indivíduos autointeressados, porém, geradores de uma ordem espontânea que surge da desordem imperada ao nível dos indivíduos no locus das situações concretas e cotidianas de relações comerciais e produtivas.

É possível que o mercado se aproxime da noção defendida por Paiva (2011) no sentido de apresentar certas propriedades de escalonamento e autossimilaridade. Isso porque é possível identificar certos padrões observados no mercado como um todo no comportamento particular dos agentes individuais que o formam, de maneira que não seria exagero inferir que o mercado está nos agentes individuais, assim como os agentes individuais estão e formam o próprio mercado como um todo, de modo similar a um fractal. Isso acaba por justificar o fato dos economistas constatarem certas relações positivas e negativas entre variáveis como preço e quantidades ofertadas e demandadas, dado que essas variáveis numa visão mais geral também obedecem à lógica psicológica e comportamental apresentada pelos agentes a nível individual.

Todavia, a imprecisão é um elemento intrínseco ao próprio sistema. Ou seja, é possível saber em linhas gerais os contornos finais do mercado e sua trajetória em curto espaço temporal, mas é difícil prever com exatidão os valores futuros de todas as variáveis importantes em períodos mais longos, assim como o caso do formato de uma árvore em que se conhecem seus contornos gerais, no entanto, sem ser possível prever onde e quando ocorrerão as suas bifurcações em escalas cada vez menores. Sobre isso, cumpre ressaltar a obra de Peters (1996) destinada a explicitar os métodos computacionais para estimar dimensões fractais e o expoente de Lyapunov em séries temporais de preços, no âmbito do mercado financeiro; e Mandelbrolt (1997) que demonstrou como se poderia avaliar o comportamento do mercado financeiro por intermédio de métodos formais e da geometria relacionada aos fractais.

É mister assinalar o fato de que os estudos em economia na maioria dos casos serem pautados em funções lineares não inviabilizam a visão do mercado como um sistema caótico. Isso 
porque a opção por se trabalhar funções lineares se justifica na conveniência metodológica e pedagógica que objetiva simplificar a dimensão integral e filosófica do mercado a construtos práticos e que subsidiem o planejamento humano.

Funções lineares e simplistas da realidade na complexa realidade econômica apenas são possíveis de serem alcançadas mediante o emprego de tratamentos estatísticos e econométricos excessivamente simplificadores dessa mesma realidade, como é o caso do Método dos Mínimos Quadrados, que resume um emaranhado de pontos a uma função que minimiza a soma dos quadrados das diferenças entre o valor estimado e os dados observados. De fato, é um dado nas estimativas de modelos econômicos que, em períodos maiores, os erros de previsão tendem a serem maiores, em detrimento do poder de previsibilidade das mesmas. Todavia, o conceito aqui empregado está menos preocupado em formular um instrumental prático e didático da realidade, e mais em engendrar uma visão mais totalizante e abstrata que se aproxime da complexidade inequivocamente apresentada pelos mercados reais de maiores dimensões numéricas, ainda que tal formulação seja obrigada a assumir um caráter meramente holístico.

Mutatis Mutandis, é fácil perceber que as variáveis em um mercado muitas vezes estabelecem uma relação de retroalimentação, de maneira que uma variável - como o preço de um produto $x$ qualquer - em períodos anteriores influi nos lucros das empresas e na decisão de consumo no período atual. Isto é, pequenas alterações nas condições iniciais do mercado, como mudanças de previsões ou um ruído qualquer, são suficientes para causarem grandes repercussões que engendram, no longo prazo, dificuldades de serem efetuadas previsões precisas e inequívocas - ainda que gravite em torno de taxas naturais por força da ação dos atratores objetivos e subjetivos desse sistema. Em outras palavras, ainda que o mercado seja um sistema atraído para alguns estados previsíveis no longo prazo, levando-o a girar em torno de taxas naturais por conta dos atratores existentes, o fato é que a fronteira dos resultados, em uma análise mais minuciosa e precisa, é fundamentalmente difícil de ser alcançada.

Tal comportamento obedece a um padrão fractal de autossimilaridade e escalonamento, pois, a sequência do comportamento futuro do mercado pode ser previsível em torno de um comportamento esperado e circunscrito, conforme demonstrado por Mandelbrolt (1997) e Peters (1996), em torno de um padrão - taxas naturais, na interpretação do presente estudo. Porém, previsões precisas na fronteira dos resultados para o mercado, em espaços de tempos maiores, definitivamente, são improváveis de serem previamente estabelecidas na presença de uma infindável gama de variáveis e rodadas de negociações estabelecidas pelos agentes, que a cada rodada aperfeiçoam suas atuações, em um processo de tentativas e erros - learnig by doing e/ou learnig by using - em um ambiente de agentes pulverizados e com suas estratégias constantemente em evolução.

Preconiza-se, nesse sentido, que os mercados são ordens espontâneas de não-equilíbrio, nos termos previstos por Hayek (1973) e que, por não ter um planejamento central, funcionam com base no comportamento pulverizado e complexo dos agentes individuais autointeressados e caracterizados pelo seu conhecimento limitado, mas que evoluem mediante o processo autoorganizativo de aprendizagem social com caráter aperiódico. Assim, esses atores individuais 
qualificam suas ações na medida em que novas rodadas de negociação vão ocorrendo e, por intermédio do processo de tentativas e erros, os mesmos atuam de maneira a gerarem uma complexificação e aperfeiçoamento do mercado como um todo que elevam os padrões institucionais, técnicos, culturais que configuram o sistema de mercado que funciona, ou funcionou em um determinado momento "t".

De novo, como os agentes aprendem com o tempo e os erros sistemáticos são evitados, há a possibilidade de que o mercado tenda para certos estados de equilíbrio - que nada mais são do que as taxas naturais - , mas que pela ocorrência de ruídos (mudanças contingenciais e circunstanciais que modificam o estado objetivo e subjetivo dos fatores) e pelo próprio fato de que os agentes aprendem e aperfeiçoam suas ações com o passar do tempo dinâmico, o sistema dificilmente atinge um estado de equilíbrio preciso e perfeito, exceto acidental e temporariamente. Assim, o máximo de previsão de longo prazo possível de ser alcançado consiste numa esperança probabilística de que as variáveis se estabilizem em torno de um padrão indicado pelas taxas naturais.

Dessa forma, a partir das explanações realizadas ao longo do presente trabalho, propõe-se conceituar o mercado como: um sistema complexo e repleto de relações não-lineares entre indivíduos autointeressados, porém, geradores de uma ordem espontânea que evolui a partir do processo de aprendizagem social, mediante tentativas e erros, que implica na complexificação e no aperfeiçoamento dos padrões institucionais, culturais e técnicos que configuram o próprio mercado ao longo de um tempo dinâmico.

Além disso, avulta-se que a instabilidade do mercado resulta de ruídos decorrentes de constantes modificações dos seus intrínsecos fatores objetivos (fatores de produção, tecnologia conhecimento, etc.) e subjetivos (revisões de expectativas, costumes, etc.), sem o comprometimento do seu processo evolutivo em função da não ocorrência de erros sistemáticos ao longo de períodos mais elásticos por parte dos agentes.

\section{CONSIDERAÇÕES FINAIS}

Em suma, se propõe que o instrumental analítico da Teoria do Caos, articulado com as hipóteses básicas de expectativas racionais, autossatisfação, tempo dinâmico, conhecimento limitado, taxas naturais e, sobretudo, ao conceito de ordem espontânea fornecidos por correntes distintas da teoria econômica, constituem um arcabouço teórico alternativo e até mesmo mais realístico e abrangente acerca da complexidade fundamental inerente a um mercado composto por uma ampla gama de agentes interagindo entre si.

Se esse for o caso, então o mercado poderá ser entendido como uma ordem espontânea hayekiana, uma vez que a pulverização dos centros de decisão, por indivíduos maximizadores de seus interesses e dotados de conhecimento limitado, engendra uma característica de não-equilíbrio no sistema, pois, a reformulação frequente das previsões e de suas expectativas, por parte dos agentes e os ruídos que constantemente engendram alterações em cadeia no mercado, implicam em frequentes alterações de sua trajetória como um todo.

Assim, embora o mercado tenda a certos estados de equilíbrio de longo prazo (taxas 
naturais) - de natureza tendencial no longo prazo decorrente do estado dos fatores objetivos e subjetivos (atratores estranhos) - assume-se que um equilíbrio de longo prazo perfeito e preciso, não facilmente seja alcançado completamente, dado que as frequentes alterações nas previsões particulares e a ocorrência de ruídos no sistema implicam no constante afastamento daquilo que seria o seu estado perfeito. O resultado desse estado de coisas é um sistema complexo e tendente ao nãoequilíbrio.

Tais argumentos tornam o entendimento do mercado como um sistema complexo e caótico não-linear pautado num mecanismo de não-equilíbrio e que evolui e se aperfeiçoa com o tempo, bastante atraente e coerente com uma noção do mercado como uma ordem espontânea hayekiana. Isto é, o conceito de ordem espontânea, quando subsidiado por outras premissas, parece muito bem ajustado ao instrumental analítico da Teoria do Caos.

Nesse sentido, a presença de propriedades como autossimilaridade e escalonamento talvez estejam por trás do fato de que muitas das características identificadas nos atores individuais também possam ser observadas no mercado como um todo e vice-versa; e no fato de que seja possível saber, em linhas gerais, a direção do mercado, mas não os valores exatos e inequívocos das suas variáveis componentes. Assim, talvez seja mister pensar no mercado como uma árvore em que, ainda que saibamos como será o seu formato mais geral, prever onde e quando ocorrerão as suas "bifurcações" seja algo intrinsecamente complicado de ser realizado.

Por fim, métodos como o expoente de Lyapunov e a análise dos erros de previsão podem constituir instrumentos de mensuração e de testes dessas especulações teóricas que, longe de intentarem constituir uma formulação acabada de um conceito de mercado, buscam provocar uma reflexão mais aprofundada da questão, mesmo que fundada numa perspectiva de todo modo holística.

O fato é que a evolução da matemática e da física, juntamente com os desenvolvimentos computacionais mais recentes, tem mostrado que talvez a natureza não seja tão previsível e "bem comportada" como os cientistas até o século XIX gostariam, e isso possivelmente sugere, em última instância, alguma lição aos cientistas sociais. Em que pese à complexidade matemática que envolve os sistemas caóticos e não-lineares, sem contar o conflito epistemológico que esses conceitos gerariam para os economistas formados numa concepção linear e determinística da realidade social e econômica; não há dúvidas de que a próxima revolução metodológica no pensamento econômico, independentemente das acepções ideológicas, terá que perpassar por uma concepção mais dinâmica e processual do sistema econômico que exigirá revisões na estrutura epistemológica que funda o cerne desse segmento científico e dos métodos de formalização dos seus principais modelos.

\section{REFERÊNCIAS}

BARBIERI, F. O ressurgimento da escola austríaca e a teoria de processo de mercado. Econômica, Rio de Janeiro, v. 10, n.2, p.215-235, 2008.

BARBOSA, W; CRISPIM, S.F. As teorias do caos e da complexidade na gestão estratégia. In: Simpósio de Excelência em Gestão e Tecnologia- SEGeT, 2006. Resende. II Simpósio de Excelência em Gestão e $\quad$ Tecnologia, 2006. $\quad$ Disponível em:< http://www.aedb.br/seget/arquivos/artigos06/834_Caos\%20e\%20Complexidade\%20Seget.pdf>.

Estudos do CEPE [ISSN 1982-6729]. Santa Cruz do Sul, n. 43, p.4-22, jan./jun. 2016. 
Acesso em: 15 ago.2015.

CORAZZA, G.; KREMER, R.L. Friedman e o monetarismo: a velha teoria quantitativa da moeda e a moderna escola monetarista. Revista Análise Econômica, n.40, set.2003.

FEIJÓ, R. Economia e filosofia na escola austríaca: Menger, Mises e Hayek. São Paulo: Nobel, 2000.

FRIEDMAN, M. The role of monetary policy. American Economic Review, 1968.

FRIEDMAN, M. Capitalismo e liberdade. Arte nova, 1977.

HAYEK, F.A. Law, legislation and liberty: a new statement of the liberal principles of justice and political economy (Rules and order). Vol.1. London: Routledge, 1973.

HAYEK, F.A. Law, legislation and liberty: a new statement of the liberal principles of justice and political economy (The political order of a free people), Vol.3. London: Routledge, 1979.

IORIO, U.J. Ação, tempo e conhecimento: a escola austríaca de economia. São Paulo: Instituto Ludwig Von Mises, 2011.

JEVONS, W. (1871). A teoria da economia política. São Paulo: Nova Cultural, 1996.

LEFFA, V.J. Transdisciplinaridade no ensino de línguas: a perspectiva das teorias da complexidade.

Revista Brasileira de Lingüística Aplicada, Belo Horizonte: Universidade Federal de Minas Gerais, v. 6, n.1, p.27-49, 2006.

LORENZ, E. Predictability: does the flap of a butterfly's wings in brazil set off a tornado in texas? American Association for the Advancement of Science, Washington, 1979.

LUCAS, J. Some international evidences on output-inflation tradeoffs. The American Economic Review, vol. 63, n.3, p.326-334, jun.1973.

LUCAS Jr, R. Expectations and the neutrality of money. Journal of Economic Theory, 4(2), p.103124, abr.1972.

MANDELBROT, B. B. Fractals and scaling in finance. New York: Springer Verlag, 1997.

MENGER, C. (1871). Princípios de economia política. São Paulo: Abril Cultural, 1983.

MISES, L. V. Ação Humana: um tratado de economia. Trad. De Donald Stewart Jr. São Paulo: Instituto Ludwig von Mises, 2010.

MUTH, J.F. Rational expectations and the theory of price movements. Econometria, 1961.

PAIVA, W. P. A Teoria do Caos e as organizações. Caderno de Pesquisas em Administração, São Paulo, v. 08, n.2, abril/junho, 85-96, 2001.

PARKER, D; STACEY, R. Caos, administração e economia. Rio de Janeiro: Instituo Liberal, 1995.

PETERS, E. Chaos and order in the capital markets. 2.ed.New York: Jhon Wiley, 1996.

PRIGOGINE, I. O fim das certezas. São Paulo: UNESP, 1996.

SARGENT, T; WALLACE, N. Rational expectations, the optimal monetary instrument, and the optimal money supply rule. Journal of Political Economy, p.241-254, abr.1975.

SICSÚ, J. A negociação da ineficácia da política monetária: uma alternativa de Keynes e dos póskeynesianos. Análise Econômica, ano 15, n. 28, p. 80-107, 1997.

SMITH, A. An Inquiry into the nature and causes of the wealth of nations. Oxford: Oxford University Press, 1976.

STACEY, R.D. A fronteira do caos. Venda Nova: Bertrand, 1995.

Estudos do CEPE [ISSN 1982-6729]. Santa Cruz do Sul, n. 43, p. 4-22, jan./jun. 2016. 
VARIAN, H. Microeconomia: conceitos básicos. 7 ed. Rio de Janeiro: Elsevier, 2006.

VELOSO, G. O; ROSA, F. A abordagem da escola austríaca sobre as formas de competição nos processos de mercado capitalista. VII Encontro de Economia Catarinense, Florianópolis: UFSC, 2013. Disponível em:<

http://www.apec.unesc.net/VII EEC/sessoes tematicas/\%C3\%81 rea\%204\%20Hist\%20Econ/ABORDAGEM\%20DA\%20ESCOLA\%20AUSTR\%C3 \%8DACA.pdf>. Acesso em: 12 ago.2015.

WALRAS, L. (1874). Compêndio dos elementos de economia política pura, São Paulo: Abril Cultural, 1983.

Estudos do CEPE [ISSN 1982-6729]. Santa Cruz do Sul, n. 43, p.4-22, jan./jun. 2016.

https://online.unisc.br/seer/index.php/cepe/index 